\title{
New Strategy for Enhancing Engineering Practical Teaching through the Development of Infrastructure Learning Hub (ILH)
}

\author{
Hesham S. A hmad'*, Wejdan A bu-Elhaija' and Yousef ${\mathrm{Q} a n d o o s^{1}}^{1}$ \\ ${ }^{1} \mathrm{~A}$ I-Zaytoonah University of J ordan, Faculty of Engineering and Technology, \\ P.O. Box: 130 A mman 11733, J ordan
}

\begin{abstract}
Site visits to construction projects are considered essential to help engineering students understand many of the topics included in the study courses. Site visits are also important in helping engineering students gain more knowledge about common procedures and materials used during the life-cycle of construction projects, and thus better prepare the undergraduate students for the real work after graduation. However, site visits for undergraduate student groups may include safety risks, in addition to the fact that trainees need to spend a considerably extended period of time for learning during the long life-cycle of construction projects. The aim of this study is to propose a project of a learning centre for engineering students that provides a safe and easy-to-reach site while allowing faster learning of engineering practices. The proposed project is its planning phase and is named Infrastructure Learning Hub (ILH). A questionnaire survey was conducted with 108 under-graduate students from the Faculty of Engineering and Technology at Al-Zaytoonah University of Jordan (ZUJ). The questionnaire aims at reveal ing the eval uation of the engineering students about the training and site visits system currently applied in the University. Also, the questionnaire seeks the engineering students' opinions about the importance of the proposed IL H and their preferable type for the project. The results of the questionnaires showed high importance for the implementation of the ILH project, and to have better coordination and scheduling for site visits with construction projects and organizations. This study intends to pinpoint the courses which require more practical emphasis in order to improve learning outcomes. The results can be very important for other engineering faculties to enhance the learning process and gain competitive advantages.
\end{abstract}

Keywords: construction, engineering students, learning, project, safety

\footnotetext{
*Corresponding author: h.ahmad@ zuj.edu.jo
} 


\section{Introduction}

Site visits to construction projects are essential for undergraduate engineering students to help them to become more familiar with the work environment, and to make them more ready for real work after graduation. Training on construction projects is not only important on the final stages of the engineering study, but it is important from the early stages to improve students' learning and understanding of the different engineering courses and subjects. A trainee needs to wait a full life-cycle of a construction project to go through all the different stages of a project, which is not possible during the limited time period specified for engineering training (about 8 weeks in ZUJ).

In the literature, some projects, especially lab-scale and computerized models, were designed and implemented for the teaching and training of students in specific engineering topics. Some studies have developed models to test the behaviour of different materials when subjected to forces, such as earthquake and wind effects. Other studies have used software programs to build virtual models for teaching students such as Building Information Modeling (BIM) and Revit software [1].

The aim of this research project is to propose a learning and training tool for engineering students to become more familiar with the different stages, tools, procedures and materials of construction projects, in a relatively high level of safety and less time and effort for learning compared with the common training process during the life-cycle of construction projects. Practical engineering exercises can be performed to improve students' understanding of various engineering topics and accelerate learning.

This study recommends designing and developing a construction project model to provide an effective learning tool for many of the engineering courses such as survey, construction materials, engineering drawings, quantity survey, infrastructure networks, concrete design, construction project management, electrical and mechanical systems design etc.

\section{Engineering Training Program and Site Visits}

The engineering training is a compulsory requirement for the engineering students in all the universities in Jordan. The main aim of the engineering training program is to train the engineering students to practice and apply the knowledge gained during the stages of their study to qualify them for the future career they desire in their speciality of study. The duration of the engineering training is normally 8 weeks, and a student can start training after finishing 3 years of the 5 years of the required engineering study. Normally, a list of qualified companies is approved by the engineering faculty, and the trainees are tested and evaluated by the training companies and by the college training supervisors. Random visits by the supervisors are conducted to ensure the commitment of the trainees.

Normally, site visits during the study semesters are non-compulsory and depend on the availability of projects which are easy to reach and access, and also depend on the motivation of the lecturers. In most of the engineering colleges, site visits are not included in the study plans or course outlines. Sometimes, one or two scientific trips are conducted during the semester which is open to interested students from different stages and enrolled in a different course. These trips either conducted during working days that contradict with the time of classes or during non-working days where many students seem to lack the motivation to attend these trips.

The aim of this study is to apply a project that motivates site visits for engineering students, whether these visits are organized by courses' lecturers or in the shape of students' individual visits. 


\section{Infrastructure Learning Hub (ILH)}

Infrastructure Learning Hub (ILH) is a project proposed to be applied in and sponsored by Al-Zaytoonah University of Jordan. The project will be designed to enhance the engineering training and site visits effectiveness for the students of the different department in the Faculty of Engineering and technology including Civil and Infrastructure Engineering, Electrical Engineering, Mechanical Engineering, Technology of Alternative Energy and Architecture. The project can also attract sponsoring from an interested organization and can provide services to people and organizations from outside the university. In the questionnaire survey of this study, the respondents were asked to choose their preferable shape of the project from the following alternatives:

1. Three-dimensional V irtual Reality (VR) technology to model a construction project, and allow users to go through the different items in the project and investigate its related work methods, tools, materials, tests, etc.

2. A $n$ interactive software program that can be accessed through the internet and provide information about construction stages, materials, tools, tests, etc.

3. A mobile application that allows users to go through a construction project and to retrieve useful information about work procedures, tools, materials, tests, etc.

4. Small size models that describe different parts of the construction project and present related information.

5. Real size building, supported by written information and monitors, that the learner can walk through and investigate the different construction stages and related materials, tools, tests, etc.

6. Real size building, supported by an electronic mobile application, that the learner can walk through to identify the different construction stages and items, and the different tools and materials used for the execution of these items. The mobile application provides detailed information for the existing items and materials as needed.

\section{Literature Review}

A study by Gharehbaghi and McManus [2] has identified important skills and abilities that learners should gain to manage construction projects effectively. The study introduced objectives which are important for construction managers such as the ability to set achievable and effective goals, monitor, and control the project, and ensure delivering work successfully within the constraints of time and budget. To achieve these objectives, construction managers should possess professional skills such as time management, resource management, budgeting, and risk management. According to the study, a successful manager must also know how to give the right task to the correct person, how to involve the client in the stages of the construction project and know the closeout procedure of the project.

Two studies by Cline [3, 4] has identified and discussed teaching strategies of construction project management in higher education. In the first study, Cline [3] has determined key competencies needed by construction project managers. It was found that the five most important skills for effective project management are leadership, construction management, professional and ethical judgement and plan reading.

In the second study by Cline [4], qualitative interview method was conducted with ten current faculty members of U.S. construction management colleges to determine which teaching strategy is the most often used when teaching construction management students. 
The teaching strategies used in this study have been developed in the previous study by Pratt [5] who developed a conceptual framework of teaching in higher education. Pratt's study developed five different perspectives on teaching, including Social Reform, Nurturing, Transmission, Apprenticeship and Developmental Perspectives. The results of Cline's study showed that the developmental (i.e. "Teaching must be planned and conducted from the learner's point of view" [5]), and transmission (i.e. "The 'stand and deliver' approach requires the teacher to accurately put forth to the student the content to be delivered" [5]) perspectives were the most commonly used perspectives in teaching. Although the transmission perspective was found to be the most commonly used by the interviewees, they all believed that transmission teaching could be the least effective of all perspectives.

Accreditation standards and criteria for construction education programs were developed by the American Council for Construction Education [6]. These standards emphasize that effective construction management curricula should be responsive to evolving construction knowledge, technologies, and management trends.

\section{Related Existing Practices}

A study by Magoha [7] has discussed the methods and tools existing at the time of conducting the study to enhance the effectiveness of the training of engineers and technologists. According to the author, the development of new technologies has encouraged the achievement of new engineering training concepts. The study has recommended interactive methods to make engineering teaching and learning more interesting. The study has proposed effective instructional methods for training engineers and technologists, including the computer as an engineering design tool, virtual reality, multimedia (a combination of audio and visual materials), teaching and learning with the internet (e-learning), web-based engineering experiments and modular engineering teaching equipment. The author argued that the effectiveness of the teaching or learning methods to be used depends on the objectives of learning, group size, local constraints, students' abilities, teacher/student preferences, type and level of learning, and availability of time and facilities.

\section{Study Objectives}

Site visit of construction projects is normally an important practice used to improve understanding of engineering students to many of the topics in the engineering courses. In these visits, students can only see a few stages of the construction processes. To see most of the construction stages, trainees need to spend a long time during the project life-cycle. Also, the site visits can be associated with a high level of safety risk for the large groups of students.

This project aims at proposing a model of a construction project. This model can help to show variable stages, procedures, tools and materials of construction projects effectively with a high level of safety for students' groups. Various exercises and procedures can be applied in this project and many engineering related information can be introduced to help accelerate learning and improve understanding of different engineering topics. Also, the project will provide practical training that makes students more familiar with projects and more ready for work after graduation.

A questionnaire survey was conducted to evaluate the existing procedures and systems followed for engineering training and site visits. Also, the questionnaire assesses the expected usefulness and effectiveness of the proposed project (ILH) in the opinion of the engineering students. It is expected that this project will help educators in the teaching process, and will help students to learn better, faster and safer. 
The proposed project (ILH), if applied successfully, can provide competitive advantages for engineering graduates in the engineering industry. The project can improve knowledge and skills for the engineering students to make them more ready for the work after graduation. Also, it will help students to better understand different engineering topics during the different engineering courses.

\section{Questionnaire Survey}

\subsection{Questionnaire Objectives}

The main aim of the questionnaire survey is to investigate and evaluate the opinions of engineering students about the engineering training and site visiting procedures currently used in the Faculty of Engineering and Technology in ZUJ, and the opportunity to develop these procedures by proposing a project (ILH) for engineering learning development. The questionnaire is composed of three main sections.

The first section asks respondents to provide their information such as speciality and stage of the study. The second section is dedicated to investigating the opinions of respondents about the effectiveness and sufficiency of the existing engineering training and site visit procedures. This section also includes an open-ended question that asks respondents to provide briefly, according to their opinions, a list of the most important constraints that negatively affect the effective implementation of site visits to construction projects.

Finally, the third section seeks the students' evaluation of the importance of a proposed project (ILH) that should be easy for students to reach and should enhance learning during their engineering study and also to enhance qualification for engineering career after graduation. This section also asks the respondents to select from different alternatives their preferable type for this project, and optionally to provide their additional ideas and suggestions.

\subsection{Sample Analysis (Section 1)}

From a population of about 1,000 students enrolling in the Faculty of Engineering and Technology, 165 students were contacted that represent about $16.5 \%$ of the population. This percentage is greater than the recommended percentage in previous studies [8]. The questionnaire was distributed electronically to students in courses which are normally enrolled by fourth and fifth-year civil engineering students. This student-level of the study was chosen to ensure that the questionnaire respondents have a high level of awareness about the subject of engineering training and site visits.

With a response rate of about $68.5 \%, 113$ students have completed the survey. Five poor responses were rejected, to makes the total number of accepted questionnaires for the analysis equals 108 responses. Most of the accepted respondents (about 95\%) are studying civil engineering, and only 5\% are studying mechanical and architectural engineering. Also, the majority of the accepted respondents are undergraduate students in the $4^{\text {th }}$ year $(60 \%)$ and $5^{\text {th }}$ year $(33 \%)$. The rest of the respondents are graduates $(3 \%)$, and students in the $3^{\text {rd }}$ year $(3 \%)$ and $2^{\text {nd }}$ year $(1 \%)$.

\subsection{Evaluation of Existing Procedures (Section 2)}

The results of the second section of the questionnaire evaluate the existing adopted training program and assess the importance of site visits during the enrollment in the engineering 
courses. The results indicated that only about $54 \%$ of the respondents are agreeing and strongly agreeing that the training program adopted in the study plan is adequate for providing the knowledge and skills required for effective starting of their career after graduation. Also, only about $50 \%$ of the questionnaire respondents feel that the existing training program adequately support the learning and understanding process required during the enrollment in engineering courses.

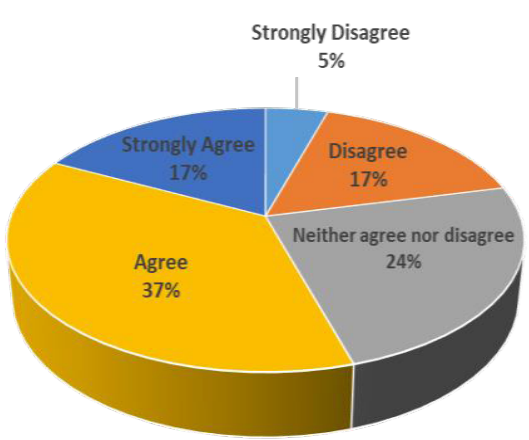

Existing training program is adequate for giving the knowledge and skills required for work after graduation.

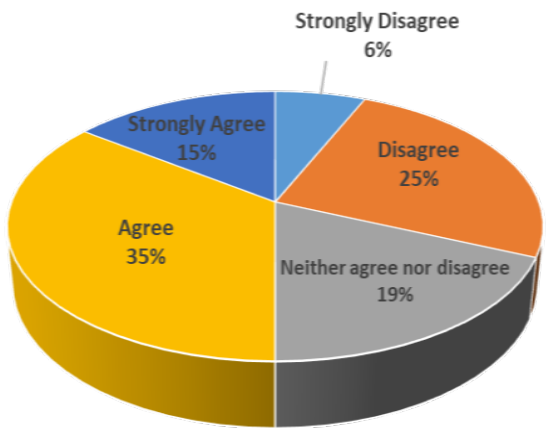

Existing training program is adequate for giving the learning and understanding required during course enrollment.

Fig. 1. Adopted Training Program Adequacy for Professional Qualification and Study Learning

Furthermore, the results showed that $98 \%$ of the respondents agree and strongly agree that site visits during the enrollment in engineering courses are needed and important for the effective learning and understanding of engineering courses. Only $26 \%$ of the respondents feel that the site visits conducted during their enrollment in the engineering courses are adequate for the effective learning and understanding of the course contents.

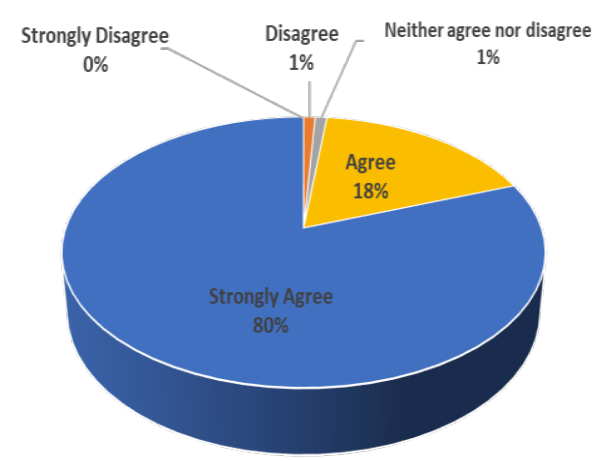

Site visits are needed and important during enrollment in courses for learning and understanding of courses.

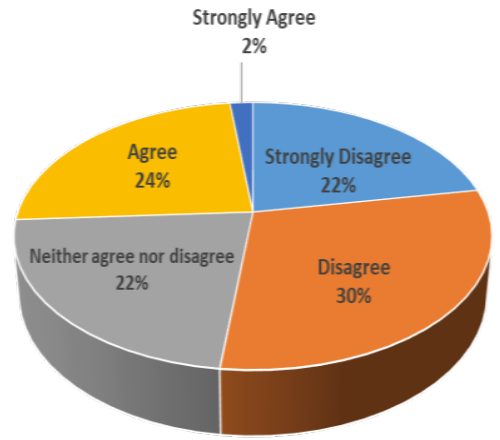

Site visits conducted during enrollment in courses are adequate for learning and understanding of courses.

Fig. 2. Importance and Adequacy of Site Visits during Enrollment in Courses 
The last question in the second section is an open-ended optional question that asks respondents to briefly list the most important constraints, which in their opinion cause lack of effective site visits during their enrollment in the engineering study. This question was completed by 67 respondents, resulted in 136 points categorized and listed in Table 1. The written constraints by respondents resulted in 28 sub-constraints categorized into five main groups of constraints.

As shown in Table 1, the constraints related to time are the most constraints written repeatedly in the respondents' answers, followed by the constraints related to coordination, and then awareness. Factors such as Time pressure for students during the study semester, time conflict between the course classes and site visits, lack of coordination between the department and engineering organizations, and difficulty of transportation to sites are the most constraining factors discussed by the respondents. Furthermore, factors such as lack of students' awareness and motivation for the importance of engineering site visits, and not including the site visits in course plans and descriptions, are moderately discussed in the responses.

Table 1. Constraints of Site Visits during Enrollment in Courses

\begin{tabular}{|c|c|c|}
\hline $\begin{array}{c}\text { Main } \\
\text { Constraints } \\
\end{array}$ & Sub-Constraints & $\begin{array}{l}\text { Number of } \\
\text { Responses }\end{array}$ \\
\hline \multirow[t]{9}{*}{ 1. Awareness } & 1.1. Student lack awareness and/or interest & 7 \\
\hline & 1.2. Student lack of motivation & 6 \\
\hline & 1.3. Lecturers lack awareness and/or interest & 5 \\
\hline & 1.4. Management lack of awareness and/or interest & 4 \\
\hline & $\begin{array}{l}\text { 1.5. Projects' managers are unwilling to allow site } \\
\text { visitors }\end{array}$ & 3 \\
\hline & $\begin{array}{l}\text { 1.6. Difficulty for students to connect the theoretical } \\
\text { knowledge with its application in the field }\end{array}$ & 1 \\
\hline & $\begin{array}{l}\text { 1.7. Students unawareness of the work terms in } \\
\text { projects }\end{array}$ & 1 \\
\hline & 1.8. Site engineers are unwilling to give information & 2 \\
\hline & Total $=$ & 29 \\
\hline \multirow[t]{10}{*}{ 2. Coordination } & $\begin{array}{l}\text { 2.1. Lack of coordination with organizations and } \\
\text { projects }\end{array}$ & 15 \\
\hline & 2.2. Difficulty of organizing large number of students & 4 \\
\hline & 2.3. Lack of cooperation from students & 1 \\
\hline & 2.4. Site visits not included in course plan or syllabus & 7 \\
\hline & $\begin{array}{l}\text { 2.5. Lack of clear definition and objectives for a site } \\
\text { visit }\end{array}$ & 1 \\
\hline & $\begin{array}{l}\text { 2.6. Lack of available skilled people to provide } \\
\text { information and take responsibility during visit }\end{array}$ & 5 \\
\hline & 2.7. Difficulty of getting management approvals & 4 \\
\hline & 2.8. Poor planning beforehand & 2 \\
\hline & $\begin{array}{l}\text { 2.9. Lack of coordination between students and } \\
\text { Instructors }\end{array}$ & 1 \\
\hline & Total $=$ & 40 \\
\hline \multirow[t]{6}{*}{ 3. Time } & 3.1. Time pressure for students during semester & 17 \\
\hline & 3.2. Time conflict between classes and site visits & 15 \\
\hline & 3.3. Need for multiple visits to see variable stages & 5 \\
\hline & 3.4. Time pressure for lecturers during semester & 3 \\
\hline & 3.5. Time pressure for engineers in projects & 1 \\
\hline & 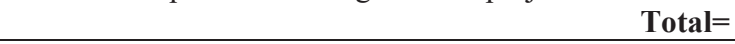 & 41 \\
\hline \multirow[t]{4}{*}{ 4. Safety } & 4.1. Lack of project safety awareness for students & 5 \\
\hline & 4.2. Lack of safety tools & 1 \\
\hline & 4.3. Low safety level inside project sites & 2 \\
\hline & Total $=$ & 8 \\
\hline
\end{tabular}


5. Location

5.1. Unavailability and difficulty of transportation

5.2. Cost of transportation

4

5.3. Lack of projects inside or near the University

4

Total=

Total of all responses $=$

18

136

\subsection{Importance and Types of the Proposed Project (ILH) (Section 3)}

In the third part of the questionnaire, a project (ILH) was proposed as a model that can provide students with important practical information normally learned from engineering site visits and engineering training. The project is supposed to provide a safe site that is easy to reach. One of the expected objectives of this project is to represent variable types of works with its different details and materials for the different items and stages during the construction project life-cycle. This part of the questionnaire survey is dedicated to evaluating the importance of the proposed project and the preferred type for it according to the opinions of engineering students.

The first question in the third section asked the respondents to evaluate the importance of the proposed project (ILH) for students to gain knowledge and skills required for effective starting of specialized engineering jobs. The second section investigates the evaluation of respondents for the importance of the proposed project (ILH) to gain effective learning and understanding during enrolled courses. The results of the two questions, as shown in Figure 4, indicate the high importance of the project (ILH) in the opinions of the engineering students.
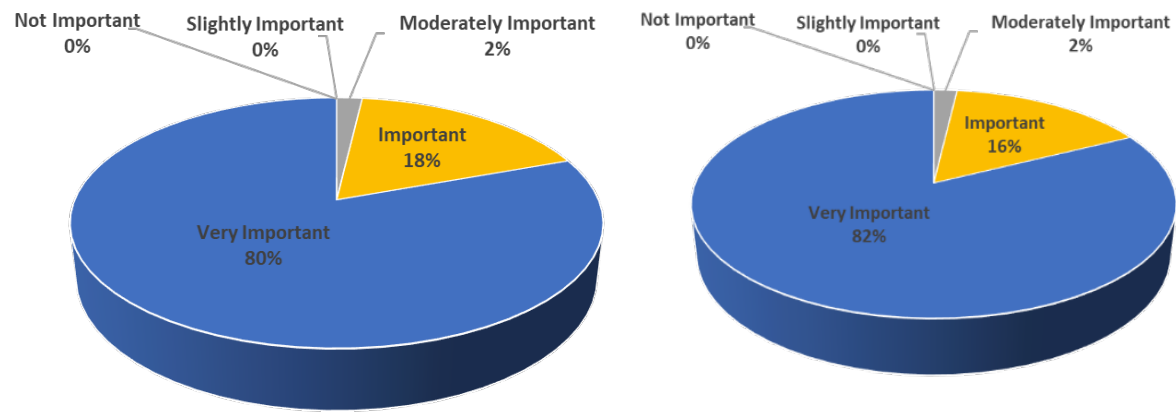

Importance of developing an engineering project (IL H) that helps supporting knowledge and skills required to work effectively after graduation.
Importance of developing an engineering project (ILH) that helps providing effective learning and understanding in the enrolled courses.

Fig. 3. Importance of ILH for the Engineering Students

Finally, the third question in the third section seeks the preferences of the respondent engineering students for a number of suggested types or forms of the proposed project. The respondents were permitted to choose more than one answer if they have a similar preference for several alternatives. Also, the respondents were asked to ignore the financial factor when they make their selection. Adding other suggested solutions were also enabled for the respondents.

The results, as shown in Figure 5, showed that the most preferable type of the proposed project in the opinions of the questionnaire respondents is to develop a real-size building, supported by electronic application, the learner can walk through it to identify the different 
construction stages and items, and the different tools and materials used for the execution of these items, accompanied with a mobile application that provides detailed information for items and materials when needed. The second preferable type of the project, as shown in Figure 5, is applying three-dimensional virtual reality technologies to model a construction project, and allow users to go through the different items in the project and investigate its related work methods, tools, materials, tests, etc.

The respondents provided additional comments to their answers such as: "Models that describe the different tests required during the execution of projects can be added to the project", "I suggest to coordinate scheduled and well-organized visits with the help of interested construction organizations to go to a list of projects during important stages of the projects", "I suggest developing a real-size building with every section of the building supporting a specific course", "The building should show the details required to enhance the awareness and understand of the subjects of engineering design", and "This project should be supported with the various materials, tools and modern equipment used in construction projects".

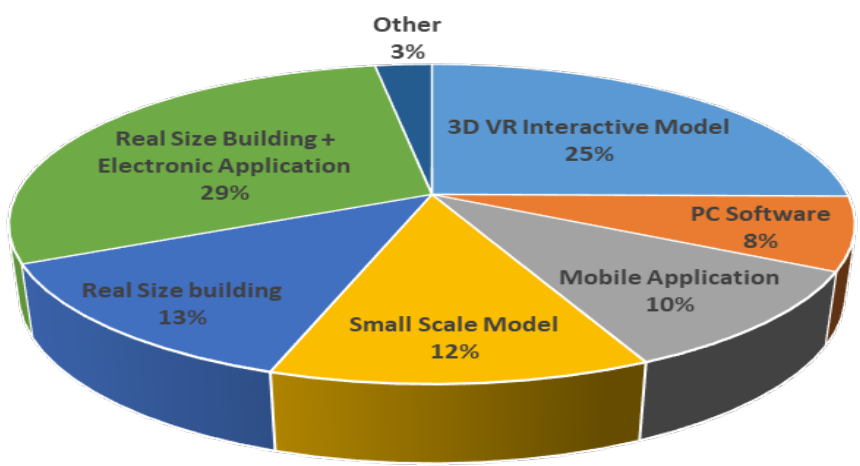

Fig. 4. Types for a Proposed Project for Engineering Learning Selected by Respondents

\section{Conclusion}

This study has highlighted a proposed project for developing a construction project model named Infrastructure Learning Hub (ILH) dedicated to providing a safe and effective place for students to practice engineering training and site visits. The project should be designed to provide information on the different stages and items of construction projects combined with the needed procedures, tools, equipment, materials and tests. A questionnaire survey was conducted (with a total of 108 accepted responses) to evaluate the existing training system and site visits for engineering students according to their opinions.

Furthermore, the proposed project was introduced to engineering students, and then the students were asked to evaluate the importance of the project and to decide their preferable shape for it. Most of the respondents to the questionnaire are students in the Civil Engineering Department in the 4 th and 5 th year (final year) of their study.

The conclusion of this study can be summarized as follows:

- About half (50-54\%) of the respondents have not agreed that the existing training program is adequate to gain the required knowledge and skill needed for effective learning and understanding the different engineering courses and to effectively start their career after graduation.

- Most of the respondents (98\%) have agreed and strongly agreed that site visits to construction projects during their enrollment in engineering courses are needed and important for effective engineering learning and understanding. 
- Only, about a quarter of the respondents (26\%) have agreed that the site visits conducted during their engineering study are adequate for the effective learning and understanding of engineering courses.

- Investigating the constraints, which cause lack of effective site visits during the engineering study, has shown that the constraints related to time pressure and lack of coordination among management, lecturers, construction organizations, and project staff, are the most critical constraints.

- The results for evaluating the importance of the proposed ILH project for learning showed that most of the respondents (98\%) see this project as important and very important for effective learning and understanding during the enrollment in courses, and for gaining the knowledge and skills required for the effective start of their career in engineering.

- Different types were proposed for the learning project (ILH). The most selected type from the alternatives was a real-size building supported by electronic application where the learner can walk through to identify the different construction stages and items, and the different tools and materials used for the execution of these items, supported with a mobile application that provides detailed information for items and materials when needed. The second preferable type of the project is applying threedimensional virtual reality technology to model a construction project and allow the user to go through the different items in the project and investigate its related work methods, tools, materials, tests, etc.

The results of this study are significant for gaining more effective planning for education and training methods and improving the effectiveness of future engineers in the construction industry. This project is still in its early stages that include analysis of end-users opinions and needs. Future stages will contain deeper planning and details of the project design, implementation and operation

\section{References}

1. A. Nejat, M .M . Darwish, T. G hebrab, BIM Teaching Strategy for Construction Engineering Students, A SEE A nnual Conference and Exposition, San A ntonio, Texas (2012)

2. K. Gharehbaghi, K. M CM anus, Effective construction management, Leadership and Management in Engineering, 3(1): 54-55 (2003)

3. R.C. Cline, Teaching key competencies of effective construction project managers to adults in higher education, Thesis (PhD), U niversity of I daho, M oscow, Idaho (2008)

4. R.C. Cline, Effective Construction Management Teaching Strategies, 118th A SE E A nnual Conference and Exposition, June 26-29, 2011, V ancouver, BC, Canada (2011)

5. D., Pratt, Five perspectives on teaching in adult and higher education, K rieger Publishing Company, M alabar, Florida (1998)

6. A merican Council for Construction Education - ACCE, Standards and criteria for accreditation of postsecondary construction education degree programs, Document 103 (2004)

7. P.W . M agoha, Effective methods and tools for training engineers and technologists: regional trends, World Transactions on Engineering and Technology Education, 1(2): 209-216 (2002)

8. M. Al-Hmadani, A . A I-J adri, A. Qandaleje, A . Bani-Hani, A bu-Zenh, Scientific research methods - fundamentals of scientific research. First edition, A mman, Jordan (2006) 